\title{
ONTOLOGICAL AND EPISTEMOLOGICAL DISCOURSE(S) ON SUSTAINABLE DEVELOPMENT: PERSPECTIVE ON SIERRA LEONE IN THE AFTERMATH OF A DECADE OF CIVIL UNREST
}

\author{
Emerson Abraham, JACKSON \\ University of Birmingham, United Kingdom, e-mail EAJ392@bham.ac.uk / emersonjackson69@gmail.com
}

\begin{abstract}
This article addresses philosophical discourses (ontology and epistemology), framing researchers' position on topical issues relating to sustainable development, particularly in relation to Sierra Leone. The country is a nation full of memories; that which has brought lasting pain in the minds of people and the use of philosophical concepts has helped to throw light on areas pertaining to the country's scope for achieving its SDGs, while at the same time, engaging with the reality of issues through open discourses. Relevant methodologies have also been addressed with the hope of bringing to the fore ontological discourses required to foster epistemic dialogue for the sustained development of the country as a whole (more so in areas like health calamities and civil crisis the country have battled itself with in the past decade). Relevant recommended points have been proposed as a way of supporting forward thinking discourses in ensuring the country is able to progress well with its planned SDGs targets.
\end{abstract}

KEYWORDS: Ontology; Epistemology; Sustainable Development, Sierra Leone; Methodology; paradigms

\section{INTRODUCTION}

This article is rooted in pursuit of an understanding of the quest for the 'existentiality of knowledge' in the discipline of sustainable development (SD), as applied in the context of Sierra Leone. Development theories have been in existence for centuries, and its discourse(s) span across different disciplines, and to name a few; economic and developmental theories, domain ontology of the 'World Wide Web (WWW)', ecological development in tracing the existentiality of living organisms, particularly mammalians (Human-beings) as evidenced in Hammond (2015).

The two concepts (ontology and epistemology) have close ties with philosophy, and are sometimes mis-conceptually used by people, possibly so because of their association with the quest for human understanding of discourses pertaining to their surroundings. The former (ontology) as defined by Gruber (1993: 2), "is an explicit specification of a conceptualization"1; in philosophical concept, this is described as a systematic account of 'existence' and being (Crotty, 1998, p. 10). The existence of concept such as 'sustainable development', can generate critical discourses amongst scholars based on reality between people / communities and its measurement (through quantitative and [or] qualitative parameters). The quest for pursuing human understanding of existence also leads to a formal pursuance of the concept of epistemology (the latter).

\footnotetext{
1 This conceptualisation is clearly expounded from an excerpt in Wikipedia online $(\mathrm{n} / \mathrm{d})$ "as the philosophical study of the nature of being, becoming, existence, or reality, as well as the basic categories of being and their relations; it is traditionally listed as a part of the
}

The concept of epistemology according to the Stanford dictionary of philosophy (2009), also cited by Bracken (2006), "is about issues having to do with the creation and dissemination of knowledge in particular areas of inquiry". Inquiry into human social epistemology of concepts (in this case, sustainable development) is strongly rooted in scientific methods of investigation akin to the deduction of certainties surrounding physical sciences, and logic as applied in mathematics (LeeKelley, 1929:1). With the control and monitoring of external conditions surrounding discourse(s), experimental outcome is likely possible to reveal the absolute truth about human behaviour connected with what constitute development that is sustainable, not only in addressing present generational needs, but also for the good of future generations.

Given the above explanation, it is evident that the two concepts (ontology and epistemology) cannot be mutually exclusive, which signify that human search in relation to the quest for sustained development is possible as a way forward in pursuance of human desire for a better standard of living, both in the present and the future. In Beck et al (1979), social science as a discipline is intended to provide an explanation of the social realms of reality as perceived by people in different walks of life; in this vein, the use of ontology and epistemology to deconstruct the concept of sustainable development is to be viewed as a critical process of investigative research involving researchers skills in uncovering the reality of human perception of their social space, supported by appropriate methodological

major branch of philosophy known as metaphysics, and also deals with questions concerning what entities exist or may be said to exist, and how such entities may be grouped, related within a hierarchy, and subdivided according to similarities and differences". 
tool[s] (Anderson and Bennett, 2003; David \& Sutton, 2004 and Bracken, 2006).

\section{STUDY RATIONALE}

Sustainable development discourse is a concept that spans across multidisciplinary fields, in pursuit of knowledge about how human interaction with its natural habitat / environment can be judiciously utilised to support the continued existence of living organisms, both now and in the future, without destroying the environment. Ontology as explained by Noy and McGuinness (n/d), 'defines a common vocabulary for researchers who need to share information in a domain'; such domain in this context is characterised by researchers' quest to investigate the social and political world through support of scientific processes to create an environment that can be sustainably maintained, irrespective of human's exploitation in pursuit of their daily livelihoods. The thought about an ontologie for this study is centred on the notion of knowledge sharing, and the analysis of human understanding of things around their environment that constitute development, held at a sustained level to support both present and future generations.

Sierra Leone has been in constant battle in keeping up with its pace of sustained development since post-independence from its colonial power (Great Britain); very challenging, and at some point seemed impossible as a result of difficulties posed by intermittent political instability, as in the case with a decade of civil unrest, and more recently, a test of God's natural calamity, the 'Ebola epidemic'. On this note, the study is intended to address the state of development in Sierra Leone (with the hope of finding sustainable solutions), while at the sometime, learning from the past, things or experiences that will supposedly help to nurture the country in a sustained pathway of developmental progress.

\section{OBJECTIVES}

The main objectives on which this study is to be hinged include the following;

- To examine a platform for sharing common understanding of Sierra Leone's ontology of developmental pathway.

- To analyse existing structures intended to support the country's pathway of sustained development and knowledge transfer.

- Provide recommended approach(s) in assisting the country in her stride towards open dialogue in addressing its own ontology for sustained development.

\section{THEORETICAL REVIEW OF ONTOLOGICAL AND EPISTEMOLOGICAL THINKING}

The concept of ontology is theoretically rooted, more so in the way of exploring knowledge that supports the way forward in reality of how resources can be judiciously utilised to enhance sustained level of growth in a country / community, with livelihoods placed at the centre of human needs. Ontological thinking dates back as early as in works produced by scholars like Adolf Reinach, "a German disciple and colleague of Husserl, though one of many early phenomenologists who, with Ingarden, found themselves unable to follow Husserl's move to a transcendental idealist position (Smith, 1978)".

As explained by Musen 1992 and Gruber 1993 (also cited in Noy and McGuinness, $\mathrm{n} / \mathrm{d}$ ), a common structure of understanding of information sharing amongst people (or with software agents as in the case with IT systems) is considered as one of the main goals of developing ontologies. Information generated on a computer system can serve as a medium through which ontological concepts, for example, dissemination of knowledge pertaining to sustainable agenda. Ontology is a way of knowledge management as addressed by Ukpe (2013: 2); in modern time, such knowledge sharing is facilitated through easy access by means of the Internet. Such ontological concept is handled by the support of servers through various portals to facilitate the dissemination of information pertaining to issues surrounding discourses such as 'sustainable development'.

Development pertaining to ontology is subjected to three phases as expounded by Ukpe (ibid) namely: the first is requirement and analysis, characterised by the defining process in the domain. The second stage is the designing and implementation, and for sustainable development programs, this is characterised by detailed planning involving suitable projects to support sustained growth in a system (monitoring is also an integral part, involving effective information sharing). The third and final step is testing and validation. The enabling of reuse of domain knowledge has been a major driving force for the surge in ontology research (Noy and McGuinness, n/d). The notion of time is a great influence in domain reuse, and in this case the development of a domain by one researcher can also be used by others for their domains. The perception of being / reality is also rooted in the notion of domain knowledge that makes it possible for researchers, and also individuals in all walks of life to expand their knowledge in aspects relating to the prospects for development and sustained progress as illustrated by Cohen et al (2007: 7) in their explanation of the concept of epistemology.

As explained by Scotland (2012: 1), ontological paradigm can be linked to their own individual conjectured assumptions, and this means that the philosophical underpinnings of the two paradigms [ontology and epistemology] cannot be easily proven or disproven. It is certainly true that different paradigms inherently possess different ontological and epistemological views (as in the case with research pertaining to sustainable development); hence knowledge underpinning their reality can be different, and hence requiring different forms of methodological approach(es) in proving their (sustained) existentiality (Scotland, ibid). The two concepts / paradigms are closely linked, and more certainly not mutually exclusive. The quest for the reality or existence of a conceptual ideology / doctrine is considered a process to determining knowledge acquisition through tests / experiments that can possibly result in fruitful outcome(s).

\section{DECONSTRUCTING UNDERSTANDING OF SUSTAINABILITY AND DEVELOPMENT CONCEPTS}

As addressed by Borne (2013), epistemological discourse around SD is centred around increase visibility of risks created around human impact on the environment. The concept is formulated on the grounds of semantics [Sustainable + Development]; that which makes it possible for individuals, researchers and sometimes government to explore possible paradigms involving ontological and epistemological exploration to explore the unknown. Deconstructing the concept in this situation entails a critical approach in people's understanding of the discourse.

As demonstrated by Lele (1991), the concept of Sustainable Development (SD) has emerged as a buzz phrase, particularly so by international aid agencies. Sustainable development history can help shape human minds on the possible pathway of a 
nation's progress. This situation is rooted in the experiences of present day developed nations which were once in the same state of struggle as it is with present day Sierra Leone (and some parts if the African sub-region). The constructed phrase (Sustainable Development developed in the 1980s) $)^{2}$ is constantly used as a multidisciplinary concept by professionals in all walks of life. The ontological root of evolutionary objectives around SD concept (the conservation of living resources) have been criticised by scholars (Sunkel, 1987 and Khosla, 1987), particularly so the work of the World Conservation Strategy (WCS) in their contributions towards reconciling the interests of developing communities, and that of environmental movement as addressed by Khosla (1987), who (extract in Lele, 1991) also pointed out that:

"that the strategy of SD itself restricted to living resources, focused primarily on the necessity of maintaining genetic diversity, habitat and ecological processes. It was also able to deal adequately with sensitive or controversial issues - those relating to the international economic and political order, war and armament, population and urbanisation"

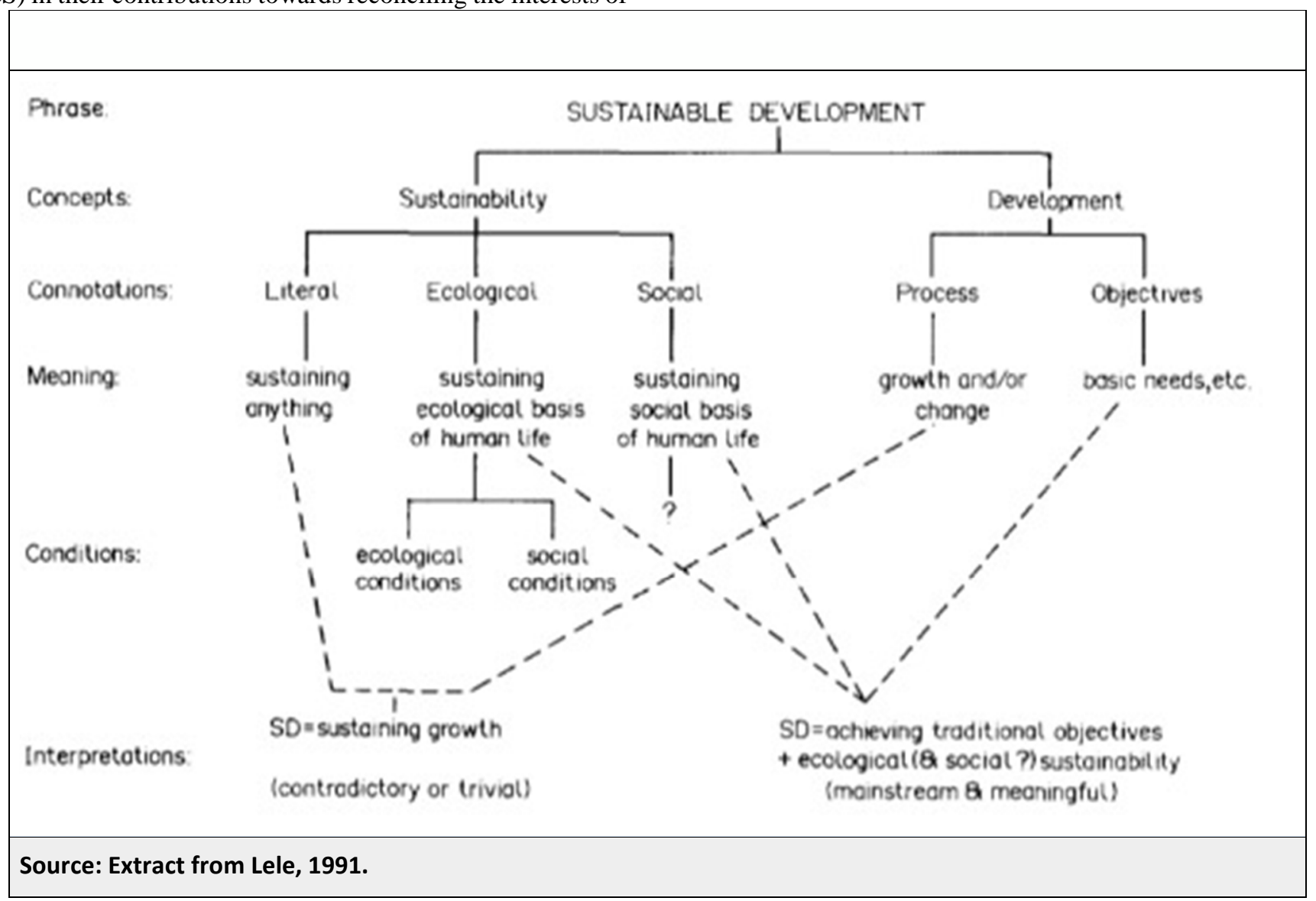

Figure 1. Semantics of Sustainable Development

Critical epistemological thinking (Sunkel, 1987) around the idea of WCS (classified as only supply side in their views of SD) has been proposed strongly for both the demand and supply side, in the event that a sustainable style of development is to be pursued; such critical views have considered WCS's approach as 'ecological sustainability' rather than 'sustainable development'.

The SD discourse has been greatly popularised through works of international organisations like UNEP as outlined by Tolba (1984):

- $\quad$ To help the very poor, because they are left with no options but to destroy their environment;

- The idea of self-reliant development, within natural resource constraints;

\footnotetext{
${ }^{2}$ This was done as part of the International Union for the Conservation of Nature and Natural Resources (IUCN) presentation to the World Conservation Strategy (WCS) with the overall aim of achieving sustainable development through the conservation of living resources (IUCN, 1980 and also cited in Lele, 1991).
}

- The idea of cost-effective development using the notion of non-traditional economic criteria;

- The great issues of health control, appropriate technology, food self-reliable, clean water and shelter for all;

- The notion that people-centred initiatives are needed.

Based on Figure 1, the SD concept (epitomising the definition of the World Commission on Environment Development [WCED3]) has been produced in its deconstructed state for human ontological thinking in the current Information Age. This has provided a deconstructed discourse of the concept to a simple mathematical equation as:

Sustainable + Development $=$ Sustainable Development $(\mathrm{SD})$

With reference to Figure 1, SD discourse is split into: (1) Sustainability (consists of 'Liberal, Ecological and Social), and (2) Development (consisting of 'Processes and Objectives'),

${ }^{3}$ The WCED definition, also cited in Jackson (2015a) is stated thus: "SD is development that meets the needs of the present without compromising the ability of future generations to meet their own needs), WCED, 1987: 43). 
thereby initiating new wave of epistemological thinking with the ultimate goal of collaborative efforts within (and amongst) multidiscipline to foster economic growth; with the focus on basic needs of people through the utilisation of available resources

\subsection{Constructive rationality for sustainable development paradigm}

Based on the work of Grin, Rotmans and Schot (2010), some school of thought have linked SD discourse to a form of transition theory based around ontological and epistemological views of 'process and variance' theories (part of Multi-Level Perspectives [MLP] on transition).

Table 1 and Figure 2: Transition and Variance Theories

Variance approach

1. Fixed entities with varying attributes.

Variables do the 'acting'.

2. Attributes have single meaning over time.

3. Time ordering among independent variables is immaterial.

\section{Emphasis on immediate causation.}

5. Generality depends on uniformity across contexts (search for laws).
Process theory

Entities participate in events and may change identity over time. Actors do the 'acting'.

Entities, attributes, events may change in meaning over time.

Time ordering of independent variables is critical.

Explanations are layered and incorporate both immediate and distant causation.

Generality depends on versatility across cases (variations within overall pattern).

Originally from Poole et al., 2000: 36

Figure 2. Transition and Variance Theories

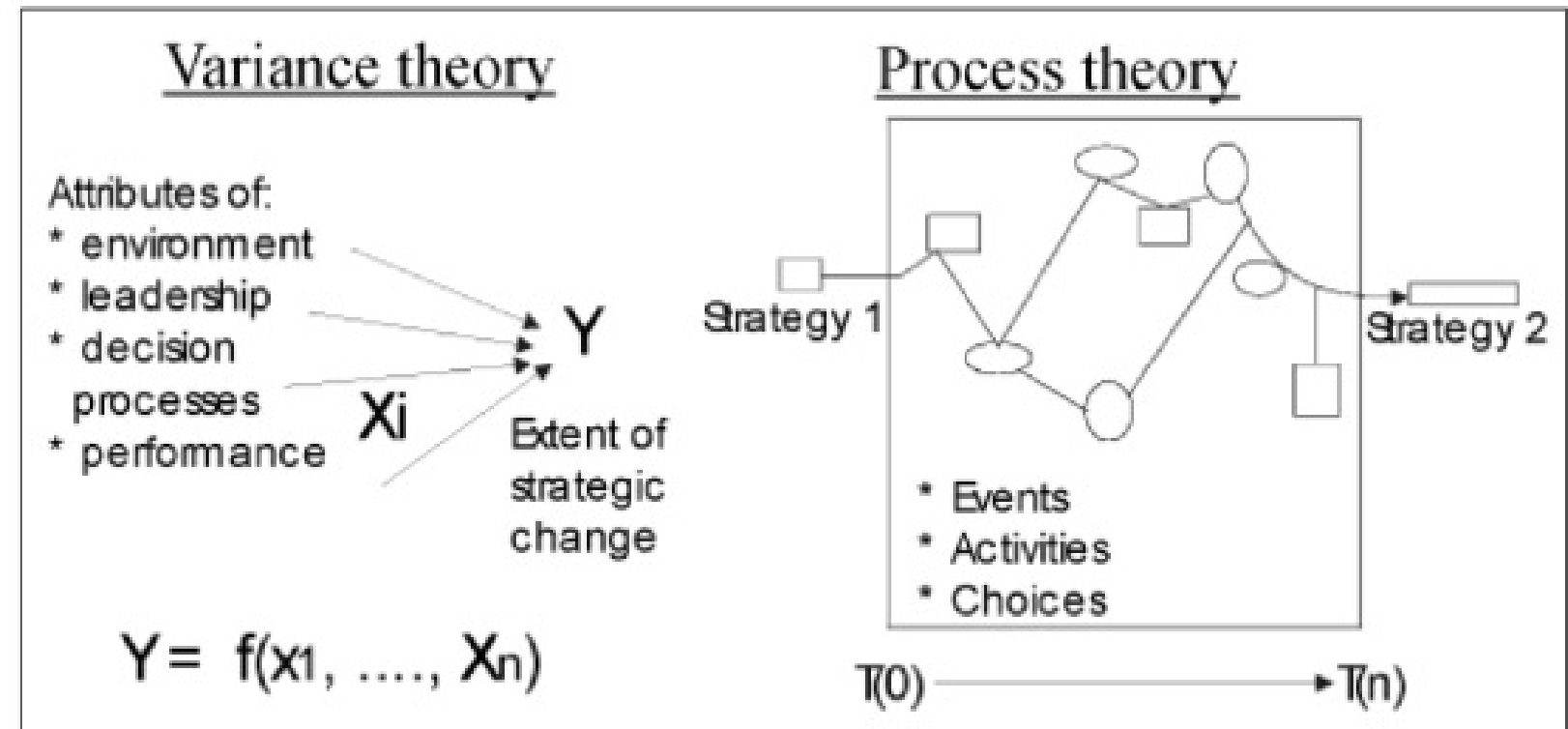

Originally from Langley, 1999: 693.

Source: Grin et al (2010).

Figure 3. Transition and Variance Theories

Table 1 and Figure 2 above provide an illustration of the concept around Variance and Process theories of transition to SD, and which Grin et al (2010) summarised as follows:

"Variance theory explains outcomes as the product of independent variables acting on dependent variables. The aim is to explain the variation / change in outcome (dependent variable) as a result of influences from causal factors (independent variables). The process approach looks at events rather than causal variables (also in Abbott, 1992)".

The ontological interpretation of the transition (Variance and Process) to SD is clearly outlined in Figure 2 as outlined by its mathematical symbolism $(\mathrm{Y}=\mathrm{f}(\mathrm{X} 1 \ldots \mathrm{Xn})$. In this vein, the $\mathrm{Y}$ function in the Variance Theory (measuring the extent of Strategic Change) is treated as a function of series of attributes which includes 'leadership, environment, processes, decision 
and performance'. In the case of the Process Theory, events are treated as 'human beings', who are considered actively engaged in the talking and epistemological process as opposed to the heavy reliance on variables; also supported by linkage to various strategies (reference to Figure 2) to ensure the transition process is fruitfully achieved.

\subsection{Methodological approaches to achieving SD}

$\mathrm{SD}$ is a growing discourse with prolific status in the agenda for development around the world; its use has sparked lots of synonyms, and to name a few 'Sustainability Science' ${ }^{4}$ and 'Ecological Sustainability (as addressed in Callicoty and
Mumford, 1997)'; the lack of clear and detailed empirical work has championed ontological quest in search of expounding knowledge pertaining to SD paradigm, supported by different types of methodological approaches as explained by Borne (2013) in his works on 'exploration discourses of SD'; this study applied qualitative methodologies using two distinct case studies as shown below in Figure 3.

The methodological approach[es] used was purely based around Ethnography, and a mix of qualitative / quantitative (akin to the concept of 'methodological triangulation'), and with its overarching merits of enhancing data Validity, particularly in the case of Borne's study where

Figure 3: Methodological Approaches for SD

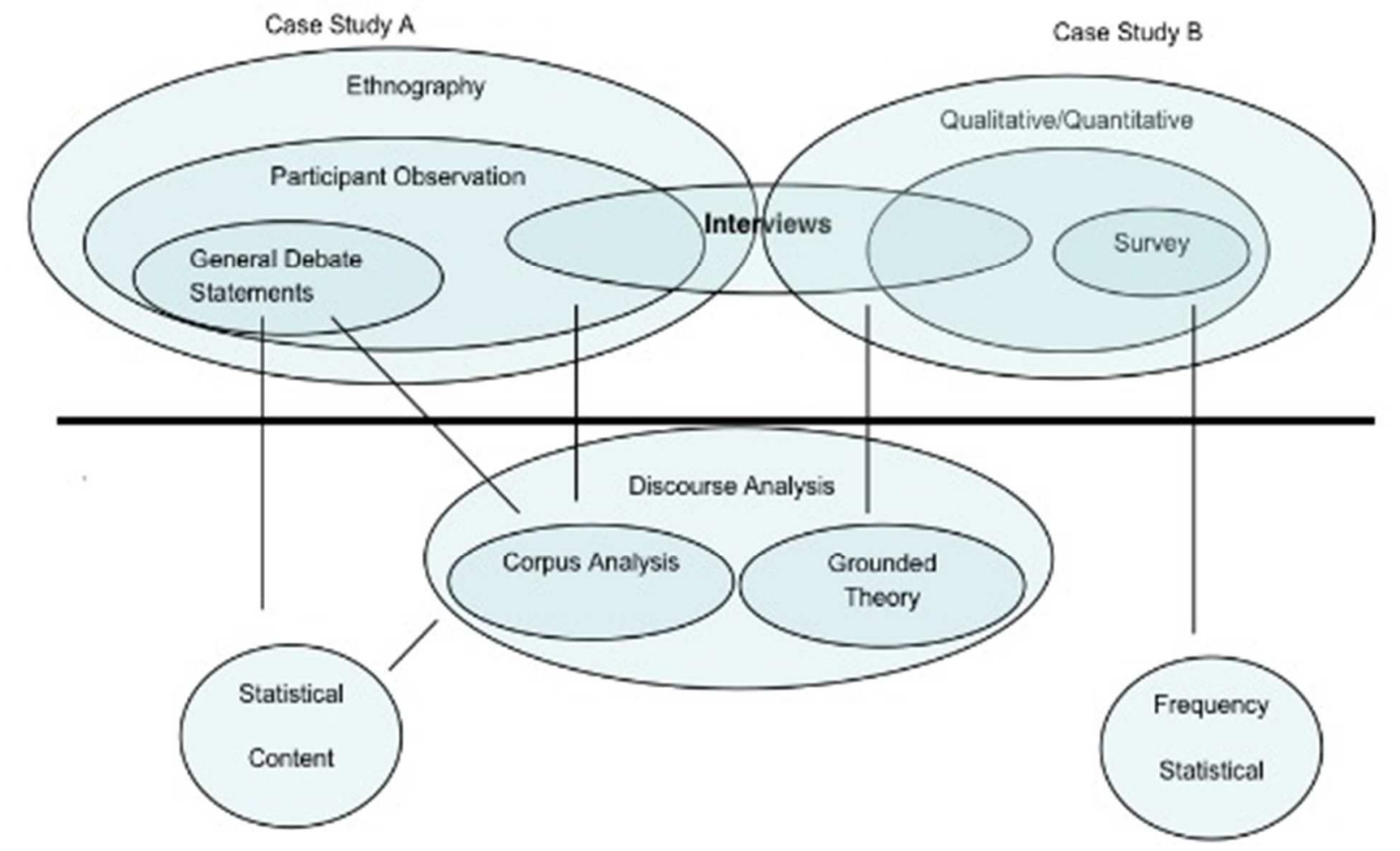

Source: Borne, 2013

Figure 4. Methodological Approaches for SD

Case Studies was applied to ascertain the effectiveness of methods applied. As explained by Hammersley (1992: 184), also excerpted in Borne (2013: 5), a case: "Is identified as any phenomenon located in time and space about which data are collected and analysed. It can comprise single individuals or a group, particular events of a situation, a specific organisation, social institution, neighbourhood, national society or global process. Case studies can address the micro situation of a single person in everyday life or the macro situation of a nation state in the global world - Case studies are defined by the focus of the instance of the phenomenon, not by the method used to study it".

Scholars such as Sala et al (2012: 11) have also attempted to adopt some of the above methods, including other structured (quantitative) approaches to identify a set of model impacts (environmental, social and economic) of SD paradigm. The outcomes from such methodological approach to knowledge acquisition is also greatly supported by ontological tools such as

\footnotetext{
${ }^{4}$ According to Sala et al (2012), sustainable science (akin to SD) is an emerging discipline, applicative and solution-oriented whose aim is to
}

'interactive systems design (Internet / WWW), and relevant software / applications' (Ukpe, 2013 and Sala et al, ibid). The scope for the use of purely qualitative approach has helped immensely in the development of emerging theoretical concept like Grounded Theory, in which data is allowed to speak for itself in order to enable epistemological theories to be. This also allows discours(es) to be continuously opened up to critical assessment given the changing circumstances in which human beings may find themselves, particularly through interaction with their natural habitation.

\section{APPLICATION IN SIERRA LEONE'S CONTEXT FOR ECONOMIC DEVELOPMENT}

This section sets the pace in addressing identified objectives, and particularly so, "an examination of the platform for sharing common understanding of Sierra Leone's ontology of

handle environmental, social and economic issues in light of cultural, historic and institutional perspectives. 
developmental pathway and the analysis of existing structures intended to support the country's milestone towards sustained development and knowledge transfer (Sections 6.1.1 and 6.1.2)". Despite a slowing process in the country, Sierra Leone like any other nation is endeavouring to take proactive steps in moving closely to meeting its commitment towards the sustainable development goals as addressed in the Post-2015 data test compiled by Braima et al (2015).

\subsection{Post-colonial Era}

The post-colonial era is characterised by the period between 1961 to present day, and with reference to the Post-2015 data test report, it provides a review of the state of the country's Sustainable Development Goals (SDG) in a bid to addressing objectives, geared towards reducing poverty in the country. It also identifies / evaluated key SDG priorities for the country in areas such as: (i) poverty, (ii) education, (iii) employment and inclusive growth, (iv) energy and infrastructure, (v) environmental sustainability and disaster resilience, (vi) governance, and (vii) global partnership for sustainable development (Braima et al, 2015).

On a positive note, the Post-2015 data test provided an opportunity for the sharing of ontological and epistemological perspectives in relation to national level targets / priorities, challenges and opportunities for the implementation of SDG. Such opportunities as addressed in the report should address area for progress and dialogue within the natural resources sector associate with corporate social responsibilities (as addressed by Jackson - 2016a).

As addressed in the Post-2015 data test report, the key area of the country's national priority for the achievements of its success in meeting the SDG (also outlined in series of the Sierra Leone's government 'Poverty Reduction Strategy Papers [PRSP I, II \& III]) seemed to have been faced with serious setbacks, more so as a result of fundamental failure(s) in addressing strategic priorities. One such key area relates to problems associated with poor access to information considered as the ontological and epistemological backbone of a nation's priorities for development which can be sustained through engagement with 'entities (people, groups and organisations) as addressed in the Process Theory for transition to SD. Priorities in the area of high investments in Information Science as addressed by Jackson (2015a) will act as a hub in supporting easy access to information from key government agencies like the 'Central Statistical Office' in ensuring the public is kept up-to-date about how best challenges set are addressed. Such challenges as addressed in the report are key to the achievement of the country's SDG, particularly so when dealing with priorities concerned with livelihood sustenance, reduction of poverty, the control of high incidence of (infant) mortality rates, gender inequality balance, reducing youth employment, and also important is ensuring attention is paid in the area of 'protecting the environment from degradation' 5 (Braima et al, 2015). On a positive note, Sierra Leone seemed to be making the effort in

\footnotetext{
${ }^{5}$ Key areas addressed in series of work produced by Jackson: Negotiating New Dimensions for Forests Conservation in Sierra Leone (2015d)

- FLEGT Mandate: its applicability and effectiveness in Sierra Leone (2015e).

- A Reflective Commentary on the Economics of Climate Change Mitigation (2015g).

- Deforestation on the Freetown Peninsula - A Case of Livelihood and Biodiversity Loss in the Goderich Community, 2015b.
}

demonstrating its commitment towards addressing the SDGs as evidenced at the UN lead SD summit held on the 25th September 2015 (tracking of the UNDPs 17 SDG, also part of the organisation's key strategic focus), but the lack of knowledge (more so poor data collection methods to allows effective dissemination of vital information) is making it hard for the country to achieve its objectives and commitments (UNDP Online, n/d and Braima et al, 2015: 87-89).

\subsubsection{Civil Unrest}

This is a period full of unpleasant memories for every Sierra Leoneans, whether in the homeland or in the diaspora; an era full of its own ontology of existing demise of the nation's infrastructural fabrics, and which today has generated a new wave of epistemology in relation to the repairing of a failed state. Sierra Leone is an endowed nation, particularly in terms of natural resources; despite all these, the country still experienced decline in economic progress and coupled with high poverty, while selfishness is making it possible for only selected few to ravage the country's natural wealth through connivance with big multinational corporations (Smillie et al, 2000 and Jackson, 2015 e and 2015f). Sustainable development pathway for the country is a dragged process, and in itself an ontological reality, due to problems of infrastructural anarchy caused during the civil war, and worse of it all, the innate selfishness of people is making it very hard for the country to achieve its desired ambition of the 2030 SDGs target.

Many scholars and researchers have pointed out the root causes of the failed state that has given rise to the civil unrest (Gberie, 2000; Munro, 2009 and Maconachie, 2008); the country is still surfacing as a debt ridden nation (with on-going problems in financing essential services like education and data / information retrieval as addressed by Braima et al, 2015), thereby making it a hard process to allow structures to be created in meeting its objectives towards the SDGs target. The way forward to minimising some of Sierra Leone's problems, particularly that which is linked to the legacy of the depletion of natural resources (diamonds and forest timber products) is through the issuing process of assurances like 'Kimberley Process Certification Scheme (KPCS)' as highlighted by Maconachie (2008), and also the 'EU FLEGT Action Plan (FAO/ITTO [2008])' as addressed in Jackson's work (2015e); this will also help attention to be focused in ensuring that the SDGs is achieved as addressed by Braima et al (2015) and UNDP (n/d). It is expected that such measures set in place will help to set out the provision for a critical ontology relating to the identified SDG, pertaining to issues around environmental degradation and more so, the sustainable use of available natural resources to protect livelihoods, while at the same time minimising vulnerability to climate change adversities.

\subsubsection{Ebola Epidemic}

The Ebola epidemic is a disaster to the people of Sierra Leone, and the 'national economy'6 as a whole, with its effects being

\footnotetext{
6 In this situation, the economy shrunk in all sectors of hopes for generating revenue to sustain livelihoods. Education was at a complete standstill with $100 \%$ lock-down of all educational establishments, thereby limiting the scope for possible ontological and epistemic engagement by academic from higher education establishments across the country; high incident rate of attrition by professional was recorded, and in some sectors, particularly in the health profession, a resulting death of prominent professional whose efforts were geared
} 
heavily felt across every corners in the country as evidenced in the 'National Ebola Recovery strategy for 2015-17 (Government of Sierra Leone, 2015); a lesson well learned about the way forward towards knowledge acquisition in the country's projected plans for the achievement of a sustained growth. The diagram (Figure 4) below provide detailed pathway of the country's milestone towards meeting its objectives on 'Agenda for Prosperity'; the calamity of the Ebola epidemic during the early part of 2014, and through to its formal end declaration announcement on the 7th November 2015 is depicted by a slump on the timing horizon scale.

\section{Figure 4: The Ebola Recovery Strategy, Agenda for Prosperity (2013- 2018, and Vision 2035}

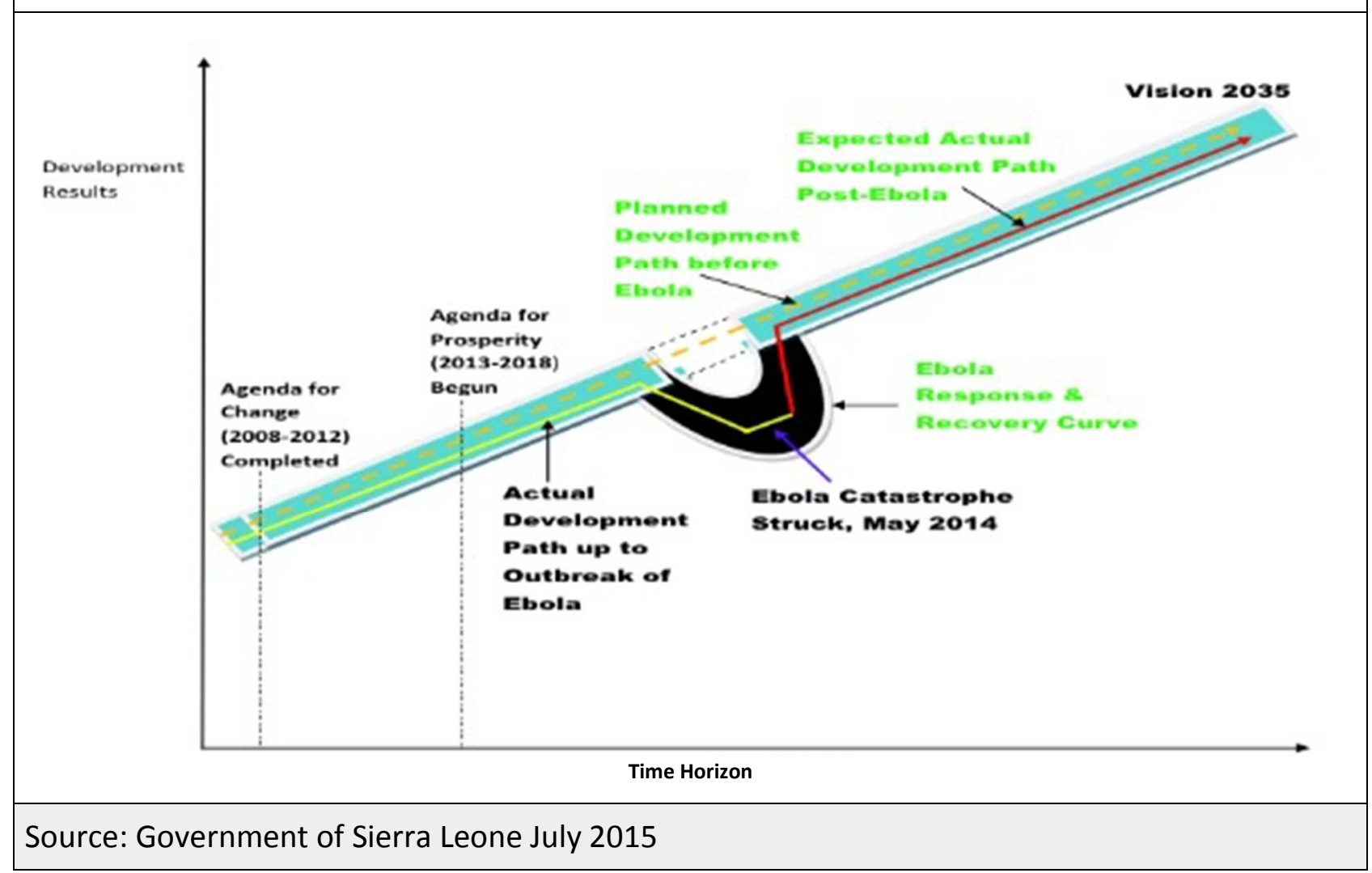

Figure 5. The Ebola Recovery Strategy, Agenda for Prosperity (2013-2018, and Vision 2035

The Ebola epidemic (in Sierra Leone), is in itself an ontological reality, unravelling issues of reflexivity and epistemology, without the need to be tied up in contentious constructivist paradigms (May and Williams, Eds., 1998). Proposition of ontological statements in this situation (such as: What is Ebola and Where did it originate from?), can be very much linked to hermeneutics (reference to Jackson, 2016 forthcoming), and this can also be contested as demonstrated in works of Outhwaite (1987). The way forward in addressing such a problem can also be linked to aspects of the country's SDGs associated with high level of investment in area like education (strongly linked to an in-depth understanding about people's culture and traditions); this may also serve as focal point in increasing citizens awareness about preventive steps, in the event of a resurgence of the deadly disease. Medium such as the Internet can also serve as a means through which people can be made aware about ontological discourse(s), and knowledge pertaining to the impact and preventive steps in curtailing its impacts at national level.

\section{CONCLUSION AND RECOMMENDATIONS}

The concepts of ontology and epistemology have been explained in general, but more specific to issues affecting sustainable development in the Sierra Leone economy. Methodological enquiry (whether qualitative, quantitative or [and] triangulation), are normally pursued as a way of exploring reality pertaining to human's quest for epistemic concepts affecting lives; so far, this study has provided some narrative discourse(s) of commonly used methods (reference to Figure 3).

This study has unraveled some detailed issues pertaining to the sustainable development of Sierra Leone, but more so linking it to everyday philosophical concepts as applied in both the physical and social sciences discipline. There has been an unraveling truth about how information science, more so the world-wide-web (WWW) can help enhance people awareness about realities affecting their well-being, as in the case with the Ebola crisis. In a similar note, education is also seen as a powerful means through which ontological discourses pertaining to knowledge concerning everyday issued such as environmental degradation, poverty and gender inequality can be addressed.

Sustainable development, even though viewed as the way forward in the achievement of a nation's future and sustained progress (in all sectors, reference to Jackson, 2015e), it also comes with challenges, more so when the fabrics (for example, high level of educational standard and attainment of citizens, good infrastructural base, good health care provision and sanitation, reliable means of data access and information systems) required to drive such progress is lacking as in the case with Sierra Leone. In order to address the country's scope for 
economic growth and sustained progress, the following points are hereby proposed as recommendation for action by state actors (but more so engaging critically with ontological and epistemological discourses);

- Efforts must be made by state actors to embrace all 17 SDGs identified by the UNDP, but more so ensuring that a review process is set up to monitor progress.

- State actors must be open to and engage with critical discourse(s) pertaining to data access and sharing. In this vein, a detailed plan must be set in place to address secured data security system for the sharing of sensitive data.

- The creation of an open forum to enable topical issues around gender equality and high (infant mortality rates are addressed so as to foster epistemic discourses in moving the country towards a sustainable pathway of development.

- An open forum is set up whereby ontological discours(es) pertaining to cultures are brought to the fore so as to make it possible to critically address issues surrounding health problems (as in the case with the Ebola epidemic).

\section{ACKNOWLEDGEMENT}

I wish to express a big thank you to Mr. Samuel J. Braima for sharing relevant information pertaining to work they have produced on the Post-2015 data test. I also acknowledge the support of colleagues in Sierra Leone for their overt expression about the choice of topic for the chosen article.

\section{REFERENCE}

10. Abbott, R. J. (1992) Plant invasions, interspecific hybridization and the evolution of new plant taxa. Journal of Trends in Ecology \& Evolution, Vol. 7(12): pp. 401-405.

11. Anderson, L. Bennett. N (2003), Developing educational leadership: using evidence for policy and practice, British Educational Management and Administration Society, London: Sage.

12. Beck, A. T., Rush, A. J., Shaw, B. F., \& Emery, G. (1979). The cognitive therapy of depression. New York, NY: Guilford Press.

13. Borne, G. (2013). Exploring Discourses of Sustainable development: A Flexible Framework. Methodological Innovations Online, Vol. 8(2): 90-106.

14. Bracken, S. (2006). Discussing the importance of ontology and epistemology awareness in practitioner research. Worcester Journal of Learning and Teaching, Issue 4.

15. Braima, S.J., Fofana, A.I., Jarrett, A.A., Kamara, J.L., Weekes, S. and Wellington, N.S.B. (2015). Measuring National Priorities for Post-2015 in Sierra Leone. July 2015, Freetown, Sierra Leone. Available at: <http://www.post2015datatest.com/wpcontent/uploads/2015/07/Final-Sierra-Leone-Data-TestReport.pdf>. (Accessed: 28th December 2015).

16. Callicoty, J.B., and Mumford, K. (1997). Sustainability as a Conservation Concept. Conservation Biology, Vol. 11(1): pp. 32-40.

17. Cohen, L., Manion, L., \& Morrison, K. (2007). Research methods in education (6th Edition). London: Routledge.

18. Crotty, M. (1989). The foundations of social research. London: Sage.

19. David, M., and Sutton, C., (2004) Social research: the basics, Thousand Oaks, CA: Sage.

20. FAO/ITTO (2008) Regional Workshop on Improving Forest Law Compliance and Governance in Tropical West Africa - Workshop Report [Online]. In http://uk.ixl.com/math/year-10/pythagoras-theorem-wordproblems. Accessed 7 February 2015.

21. Gberie, L. (2002) War and Peace in Sierra Leone: Diamonds, Corruption and the Lebanese Connection. Ottawa: Partnership Africa Canada.

22. Government of Sierra Leone (2015). NATIONAL EBOLA RECOVERY: STRATEGY FOR SIERRA LEONE (2015 2017). Government of Sierra Leone. Available at: $<$ http://ebolaresponse.un.org/sites/default/files/sierra_leone _recovery_strategy_en.pdf $>$. (Accessed: 29th December 2015).

23. Grin, J., Rotmans, J. and Schot, J. (2010). Transitions to Sustainable Development: New Directions in the Study of Long Term Transformative Change, Routlege (Taylor \& Francis Group): New York and London.

24. Gruber, T.R. (1993). A Translation Approach to Portable Ontology Specifications. Knowledge Acquisition, 5(2): pp. 199-220.

25. Hammersley, M., (1992). What's Wrong With Ethnography? London, Routledge.

26. Hammond, A.S. (2015). Everything Ape, with a Side of Human Evolution. Journal of Mammalian Evolution, Vol. 22(4): pp 599-600.

27. IUCN (1980). World Conservation Strategy: Living Resource Conservation for Sustainable Development (Gland, Switzerland: International Union for Conservation for Nature and Natural Resources, United Nations Environment Program and World Life Fund, 1980).

28. Jackson (2015a). Role of information science in sustainable development: Sierra Leone as a case study. Management of Sustainable Development Sibiu, Romania, Vol. 7(2). DOI 10.1515/msd-2015-0026.

29. Jackson, E.A. (2015b). Deforestation on the Freetown Peninsula - A Case of Livelihood and Biodiversity Loss in the Goderich Community. International Journal of Research in Agriculture and Forestry, Vol. 2(7): pp. 21-34.

30. Jackson, E.A. (2015c). Negotiating New Dimensions for Forests Conservation in Sierra Leone. Journal of Applied Thought, Vol. 4(2): pp. 85-110.

31. Jackson, E.A. (2015d). FLEGT Mandate: its applicability and effectiveness in Sierra Leone. Journal of Applied Thoughts, Vol. 4(3): pp. 84-100.

32. Jackson, E.A. (2015e). Competitiveness in Higher Education Practices in Sierra Leone: A model for Sustainable Growth. Petroleum - Gas University of Ploiesti Bulletin, Technical Series. 2015, Vol. IV(LXVII): pp. 1525.

33. Jackson, E.A. (2015f). Ethnographic Narrative of Forest Decline in the Goderich Community: The People's Perspectives. Forest Res 4:157. doi:10.4172/21689776.1000157.

34. Jackson, E.A. (2015g). A Reflective Commentary on the Economics of Climate Change Mitigation. Journal of Forest Research, Vol. 4(2): pp. 1-3. doi: 10.4172/21689776.1000142.

35. Jackson, E.A., and Jackson, H, F. (2016a). The role of Corporate Social Responsibility in improving firms' business in the directions of sustainable development, accountability and transparency. Petroleum - Gas University of Ploiesti Bulletin, Technical Series. 2016, Vol. V(LXVIII): pp. 1 - 13.

36. Jackson, E.A. and Conteh, P. (2016 forthcoming). Research Methods: A Resource for Students and PractitionerResearchers. 
37. Khosla, A. M (1987). "Alternative a Strategies in Achieving Sustainable Development". In P. Jacobs and D. A. Munro (Eds.), Conservation with Equity: Strategy for Sustainable Development (Cambridge: International Union for Conservation of Nature and Natural Resources, 1987), pp. $191-208$.

38. Lee-Kelley, T., (1929) Scientific Method: Its Function in Research and in Education, Ohio: Ohio State University Press.

39. Lele, S.M. (1991). Sustainable Development: A Critical Review.

40. Maconachie, R. (2008). Diamond mining, governance initiatives and post-conflict development in Sierra Leone. Brooks World Poverty Institute (BWPI) Working Paper 50, University of Manchester July 2008.

41. May, T. and Williams, M. (Eds.) (1998). Knowing the Social World. Buckingham, UK; Philadelphia, PA: Open University Press

42. Munro, P. G. (2009) Deforestation: constructing problems and solutions on Sierra Leone's Freetown Peninsula. Journal of Political Ecology, Vol. 16: 104 - 122.

43. Noy, N.F. and McGuinness, D.L. (n/d), Development 101: A Guide to Creating Your First Ontology. Stanford University, Stanford, CA, 94305. Available at: <http://protege.stanford.edu/publications/ontology_develo pment/ontology101.pdf>. (Accessed: 27th December 2015).

44. Outhwaite, W. (1987). New Philosophies of Social Science: Realism, Hermeneutics and Critical Theory. Basingstoke, UK: Macmillan Education.

45. Sala, S., Farioli, F., and Zamagni, A. (2012). Progress in sustainability science: lessons learnt from current methodologies for sustainability assessment: Part 1 . Int $\mathbf{J}$ Life Cycle Assess. DOI 10.1007/s11367-012-0508-6.

46. Scotland, J. (2012). Exploring the Philosophical Underpinnings of Research: Relating Ontology and
Epistemology to the Methodology and Methods of the Scientific, Interpretive, and Critical Research Paradigms. English Language Teaching, Vol. 5(9): pp. 9 - 16.

47. Smillie, I, Gberie, L and Hazleton, R, (2000). THE HEART OF THE MATTER SIERRA LEONE, DIAMONDS \& HUMAN SECURITY (COMPLETE REPORT). Partnership Africa Canada: Ontario, Canada.

48. Smith, B. (1978). AN ESSAY IN FORMAL ONTOLOGY. Grazer Philosophische Studien, 6 (19): pp. 39-62.

49. Stanford Encyclopedia (2009) Stanford Encyclopedia, Zalta, E. N. Ed. Available at; <http://plato.stanford.edu/ Online>, (Accessed 26/12/15).

50. Sunkel, O. (1987). "Beyond the World Conservation Strategy: Integrating Development and the Environment in Latin America and the Caribbean". In P. Jacobs and D. A. Munro (Eds.), Conservation with Equity: Strategy for Sustainable Development (Cambridge: International Union for Conservation of Nature and Natural Resources, 1987), pp. 35 - 54.

51. Tolba, M.K. (1984). The Premised for Building a Sustainable Society - Address to the World Commission on Environment and Development, October, 1984. (Nairobi: United Nations Environment Program - UNEP).

52. Ukpe, E. (2013). Agriculture Ontology for Sustainable Development in Nigeria. IOSR Journal of Computer Engineering (IOSR-JCE). Vol. 14(5): pp. 57-59.

53. UNDP (Online - n/d). 2030 Agenda for Sustainable Development. Available

at: <http://www.sl.undp.org/content/sierraleone/en/home/post -2015/sdg-overview.html>. (Accessed: 28th December 2015).

54. WCED (1987). Our Common Future. (New York: Oxford University Press, 1987).

55. Wikipedia Online (n/d). Ontology. Available at: $<$ https://en.m.wikipedia.org/wiki/Ontology>. (Accessed: 28th December 2015). 